\title{
Combined effects of estrogenic chemicals with the same mode of action using an estrogen receptor binding bioassay
}

\author{
Rong Yang, Na Li, Mei Ma*, Zijian Wang*** \\ Key Laboratory of Drinking Water Science and Technology, Research Center for Eco-Environmental Sciences, Chinese \\ Academy of Sciences, Beijing 100085, China
}

\section{A R T I C L E I N F O}

Article history:

Received 12 May 2014

Received in revised form

26 September 2014

Accepted 2 October 2014

Available online 12 October 2014

Keywords:

Xenoestrogen

Concentration addition

Two-hybrid yeast assay

Mixture toxicity

Mode of action

\begin{abstract}
A B S T R A C T
The increasing amounts of various estrogenic chemicals coexisting in the aquatic environment may pose environmental risks. While the concept of estradiol equivalent (EEQ) has been frequently applied in studying estrogenic mixtures, few experiments have been done to prove its reliability. In this study, the reliability of EEQ and the related model concentration addition (CA) was verified based on the two-hybrid recombinant yeast bioassay when all mixture components had the same mode of action and target of action. Our results showed that the measured estrogenic effects could be well predicted by CA and EEQ for all laboratory-made mixtures using two designs, despite the varying estrogenic activity, concentration levels and ratios of the test chemicals. This suggests that when an appropriate endpoint and its relevant bioassay are chosen, CA should be valid and the application of $\mathrm{EEQ}$ in predicting the effect of non-equi-effect mixtures is feasible.
\end{abstract}

(c) 2014 Elsevier B.V. All rights reserved.

\section{Introduction}

The development of analytical measurement and the constant pollutant discharges lead to the increasing detection rates and concentrations of endocrine disrupting chemicals (EDCs) (Petrovic et al., 2004). The reproductive and developmental toxicities of EDCs to the aquatic organisms evoke worries about the impacts on human health, and their adverse effects after the long-term exposure to environmental observed concentrations (ng/L) aggravate these worries (Hotchkiss et al., 2008; Vandenberg et al., 2012; Zha et al., 2007). Particularly, steroid estrogens (both natural and synthetic) and phenolic xenoestrogens receive more attention because of their non-ignorable estrogenicities and widespread applications (Peng et al., 2006). These substances have high or moderate affinity to the estrogen receptor (ER), mimicking the normal function of natural estrogen and disrupting the endocrine

Abbreviations: 4-NP, 4-nonylphenol; 4-t-OP, 4-tert-octylphenol; BPA, bisphenol A; CA, concentration addition; DES, diethylstibestrol; E1, estrone; E2, 17 $\beta$-estradiol; E3, estriol; EC50, half maximal effective concentration; EDCs, endocrine disrupting chemicals; EE2, 17aethinylestradiol; EED, equivalent effect design; EEQ, estradiol equivalent; ER, estrogen receptor; EV, estradiol valerate; MoA, mode of action; NOEC, no observable effect concentration; OD, optical density; RA, response addition; REP, relative potency; RMD, randomly mixed design; ToA, target of action; YES, yeast estrogen screen.

* Corresponding author. Tel.: +86106284 9141; fax: +861062849141.

** Corresponding author. Tel.: +86 106284 9140; fax: +86 1062849140.

E-mail addresses: mamei@rcees.ac.cn (M. Ma), wangzj@rcees.ac.cn (Z. Wang).

http://dx.doi.org/10.1016/j.etap.2014.10.001

1382-6689/@ 2014 Elsevier B.V. All rights reserved. 
Table 1 - Information, properties, EC $_{50}$ s and REPs of the nine test chemicals.

\begin{tabular}{llcccc} 
Abbr. & \multicolumn{1}{c}{ Name } & CAS no. & MW & EC50 & REP \\
\hline E2 & 17- $\beta$-estradiol & $50-28-2$ & 272.39 & 18.3 & 2.00 \\
E1 & Estrone & $53-16-7$ & 270.37 & $2.52 \mathrm{E}+2$ & $1.28 \mathrm{E}-2$ \\
EE2 & 17a-Ethinylestradiol & $57-63-6$ & 296.44 & $6.06 \mathrm{E}+3$ & 1.40 \\
E3 & Estriol & $50-27-1$ & 288.39 & $5.69 \mathrm{E}+2$ & $3.03 \mathrm{E}-3$ \\
DES & Diethylstilbestrol & $56-53-1$ & 268.38 & $4.53 \mathrm{E}+4$ & $3.22 \mathrm{E}-2$ \\
EV & Estradiol valerate & $979-32-8$ & 356.50 & $1.33 \mathrm{E}+5$ & $4.04 \mathrm{E}-4$ \\
4-t-OP & 4-Tert-octylphenol & $140-66-9$ & 206.36 & $1.14 \mathrm{E}+5$ & $1.38 \mathrm{E}-4$ \\
4-NP & 4-Nonylphenol & $104-40-5$ & 220.39 & $1.87 \mathrm{E}+6$ & $1.60 \mathrm{E}-4$ \\
BPA & Bisphenol A & $80-05-7$ & 228.31 & $9.82 \mathrm{E}-6$ \\
\hline
\end{tabular}

Abbr. = abbreviation; CAS = chemical abstract services registry number; $\mathrm{MW}=$ molecular weight $(\mathrm{g} / \mathrm{mol}) ; \mathrm{EC} 50$ = half maximal effective concentration $(\mathrm{ng} / \mathrm{L})$; $\mathrm{REP}=$ relative potency, $\mathrm{REP}(\mathrm{i})=\mathrm{EC}_{50}\left(\mathrm{E}_{2}\right) / \mathrm{EC}_{50}(\mathrm{i})$.

and reproductive systems. They are emitted from a variety of sources and seldom exist individually in any environmental compartment, leading to the combined adverse effects on organisms. There have been a number of surveys measuring either the estrogenic activity by use of bioassay, or concentration levels of the estrogenic substances by chemical analysis in water samples (Beck et al., 2006; Lavado et al., 2009; Mahomed et al., 2008; Matthiessen et al., 2006). To bridge the two measurements, concentrations could be transformed into biological activity using the estrogenic relative potency (REP).

In mixture toxicity research, concentration addition (CA) and response addition (RA) are two best-known and widely used models (USEPA, 2000). When taking no interaction into account, their differences mainly depend on whether all components of the mixture are toxicologically similar (Bliss, 1939; Loewe, 1928). Estradiol equivalent (EEQ) is a derived approach of CA, which just simplifies the calculation process by summing the component concentrations after adjusting them for each component's potency. In risk assessment, by comparing EEQs obtained from both analytical determination and bioassay, the major and minor contributors of a complex sample could be identified. When this was applied to environmental waters, some work reported that the predicted overall EEQs were similar to observed ones (Beck et al., 2006; Jiang et al., 2012; Liscio et al., 2009), but some found that the predictions were higher or lower (Cargouët et al., 2004; Furuichi et al., 2004). These contradictory conclusions may result from the contribution of non-targets chemicals such as unknown estrogen agonist, antagonist and humics, or the multiple involved modes of action (MoAs) and the resulting interaction of mixture components (Villeneuve et al., 2000). However, few studies have focused on the adaptations of EEQ and REP which are essential in the causality analysis. Thus, there is a need to confirm the validity of CA and EEQ for the most common ER-binding effects and EDCs with high detection rates by conducting a certain bioassay and eliminating the disturbance of other chemicals.

In the present study, we aimed to test the validity of CA and EEQ in calculating the binding capability to ER when the MoA and target of action (ToA) of all components are the same. To achieve the goal, we adopted a two-hybrid recombinant yeast bioassay to study the combined effects: the dimerization of ERs with estrogens leads to the conformational change of the ligand-receptor complex; then, the recruitment of coactivator and the transcription and translation of downstream reporter gene occur. Like the one-hybrid yeast estrogen screen (YES), this assay also offers single MoA (binding to ER) and ToA (ER). However, it is consistent with the in vivo tests better through introducing the co-activator (Li et al., 2008b; Sheeler et al., 1999). During each experiment, the high purity of yeast strain and setting of control groups should be guaranteed for the validity of test results.

\section{Materials and methods}

\subsection{Chemicals}

Estrone (E1, 99\%), 17 $\beta$-estradiol (E2, 97\%), estriol (E3, 97\%), bisphenol A (BPA, 99\%), and dimethyl sulfoxide (DMSO, 99.5\%) were purchased from Sigma-Aldrich (St. Louis, MO, USA). 17aethinylestradiol (EE2, 99\%), diethylstilbestrol (DES, 98\%), and estradiol valerate (EV, 99.5\%) were purchased from Dr. Ehrenstorfer $\mathrm{GmbH}$ (Augsburg, Germany). 4-Tert-octylphenol (4-t-OP, 97\%) was obtained from Sigma-Aldrich and 4-nonylphenol (4NP, a mixture of branched chain isomers) was purchased from Tokyo Chemical Industry (Tokyo, Japan). Information on the test chemicals is listed in Table 1. All the test chemicals were dissolved in DMSO and stored below $-20^{\circ} \mathrm{C}$. They solved well and existed stably in the standard solution and diluted gradients, and the short exposure time would not change their concentrations in culture medium (Knox et al., 2011; Tetko et al., 2005). Therefore, the actual and nominal concentrations were considered in good agreement with each other.

\subsection{Experimental design for the mixtures}

Nine representative estrogenic chemicals were selected for mixture preparation, which have been frequently detected in aquatic environment and demonstrated to play a role in estrogenic pollution. They included three natural estrogens (E1, E2, and E3), three synthetic estrogens (EE2, DES, and EV) and three phenolic compounds (4-t-OP, 4-NP, and BPA). Two experimental designs were applied to create the laboratory produced mixtures: some were made to cause equal estrogenic effects, and some were arranged according to the related environmental concentrations.

Initially, twelve mixtures (M1-M12), including two mixtures with three components, six with four components, three with five components, and one with nine components, were 
designed by an L12 $\left(9^{2}\right)$ orthogonal array. M13-M16 were gained in a similar way, containing the three phenols only to test the performance of models for weaker estrogenic effectors. Each mixture was prepared using a fixed ratio in which all components were combined at equipotent concentrations (according to their REP values), to ensure that every one of them lead to even effects, and their total agonistic activities equaled to the maximum one of E2 (an equivalent effect design, EED, Table 2). Seven concentration gradients of each of the $16 \mathrm{mix}$ tures were obtained by double dilution to cover the main part of the concentration-response sigmoid curve.

To further confirm the results of EED test, another 15 mixtures (S1-S15) were created by mimicking some actual environmental levels of the test chemicals. Their compositions and concentrations were references to several surveys of estrogenic chemicals in surface water and wastewater samples from different cities and river valleys of China (see details in Table 3). Thus, the 15 chemical profiles of these samples were used for a randomly mixed design (RMD) test. For each synthetic mimic mixture, we tested five concentration gradients which were $0.1,1,10,100$ and 1000 folds of actual concentrations in water samples to get its concentration-response relationship and the observed EEQ value. During dilution, DMSO was also served as the solvent, with a $0.5 \%$ final concentration in exposure cultures which will cause no cytotoxicity to the yeast cell.

\subsection{Bioassay}

The assays were carried out as previously described (Li et al., 2008a), and all tests were conducted in quadruplicate. Each group consisted of a positive control (E2 for the ER inductive effect), a negative control (DMSO), and test samples. After overnight culture of the yeast strain at $30^{\circ} \mathrm{C}$ and mixing at $130 \mathrm{rpm}, 5 \mu \mathrm{L}$ of the control or test sample was added to $995 \mu \mathrm{L}$ of medium containing $5 \times 10^{3}$ yeast cells $/ \mathrm{mL}$. Two hundred microliters of the control/test culture was transferred to a well in a 96 -well plate and incubated at $30^{\circ} \mathrm{C}$ with vigorous orbital shaking $(800 \mathrm{rpm})$ on a titer plate shaker (Heidolph TITRAMAX 1000, Hamburg, Germany) for $2 \mathrm{~h}$. The optical density (OD) at a wavelength of $600 \mathrm{~nm}$, which indicated cell density of the culture, was measured (TECAN GENios A-5002, Salzburg, Austria), and then a $50 \mu \mathrm{L}$ aliquot of the culture was transferred to a new well plate. After adding $120 \mu \mathrm{L}$ of Z-buffer $\left(16.1 \mathrm{~g} / \mathrm{L} \quad \mathrm{Na}_{2} \mathrm{HPO}_{4} \cdot 7 \mathrm{H}_{2} \mathrm{O} ; 5.5 \mathrm{~g} / \mathrm{L} \quad \mathrm{NaH}_{2} \mathrm{PO}_{4} \cdot \mathrm{H}_{2} \mathrm{O} ; 0.75 \mathrm{~g} / \mathrm{L} \mathrm{KCl} ;\right.$ $0.246 \mathrm{~g} / \mathrm{L} \mathrm{MgSO}_{4} \cdot 7 \mathrm{H}_{2} \mathrm{O}$ ) and $20 \mu \mathrm{L}$ of chloroform, the assay solution was carefully mixed at $30^{\circ} \mathrm{C}$ for $10 \mathrm{~min}$. The enzymatic reactions were started by adding $40 \mu \mathrm{L}$ o-nitrophenyl- $\beta$-Dgalactopyranoside ( $13.3 \mathrm{mmol} / \mathrm{L}$ in Z-buffer), and the sample was incubated at $30^{\circ} \mathrm{C}$ for $60 \mathrm{~min}$. The reactions were terminated by adding $100 \mu \mathrm{L} \mathrm{Na} \mathrm{CO}_{3(\mathrm{aq})}(1 \mathrm{~mol} / \mathrm{L}) .200 \mu \mathrm{L}$ of the supernatant was then transferred into a new well plate and the absorbance at $420 \mathrm{~nm}$ was determined. The $\beta$-galactosidase activity was calculated using Eq. (1):

$U=\frac{(O D 420 s-O D 420 b) D}{t \times V \times O D 600}$

where $U$ is the $\beta$-galactosidase activity, OD420s and OD420b are OD values of the enzymatic reaction supernatant of the
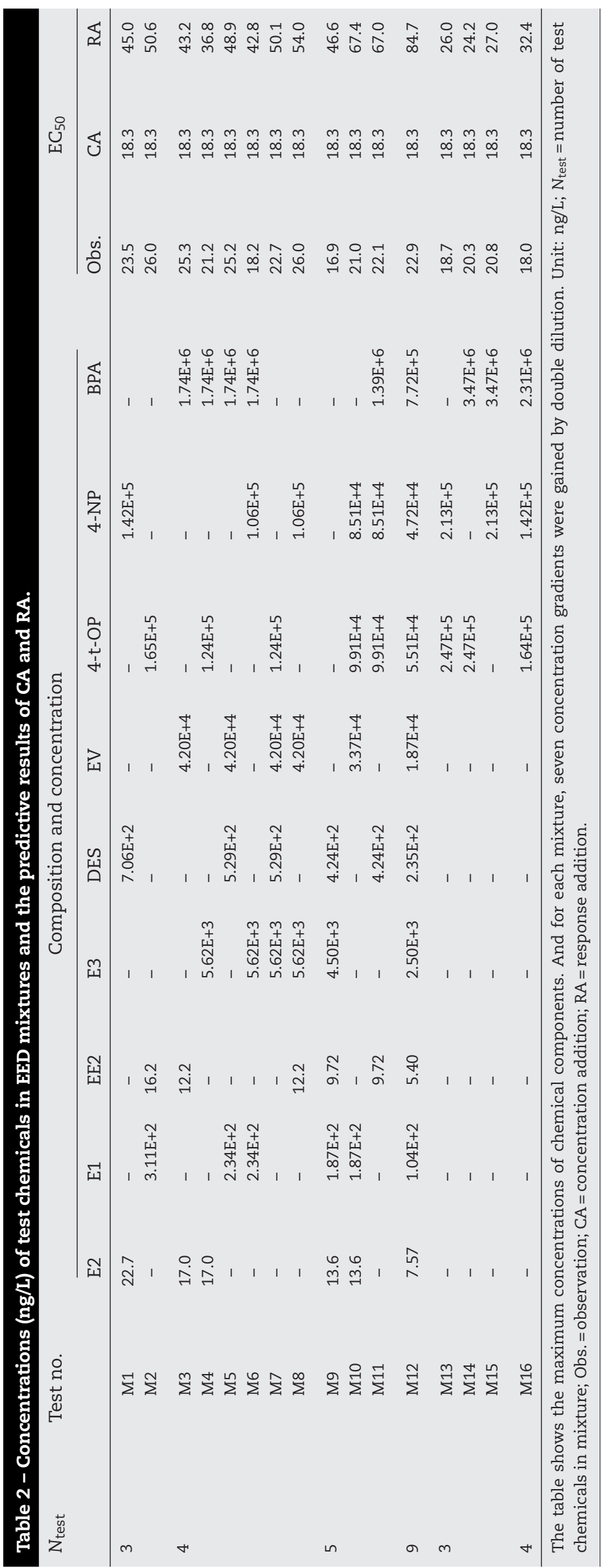


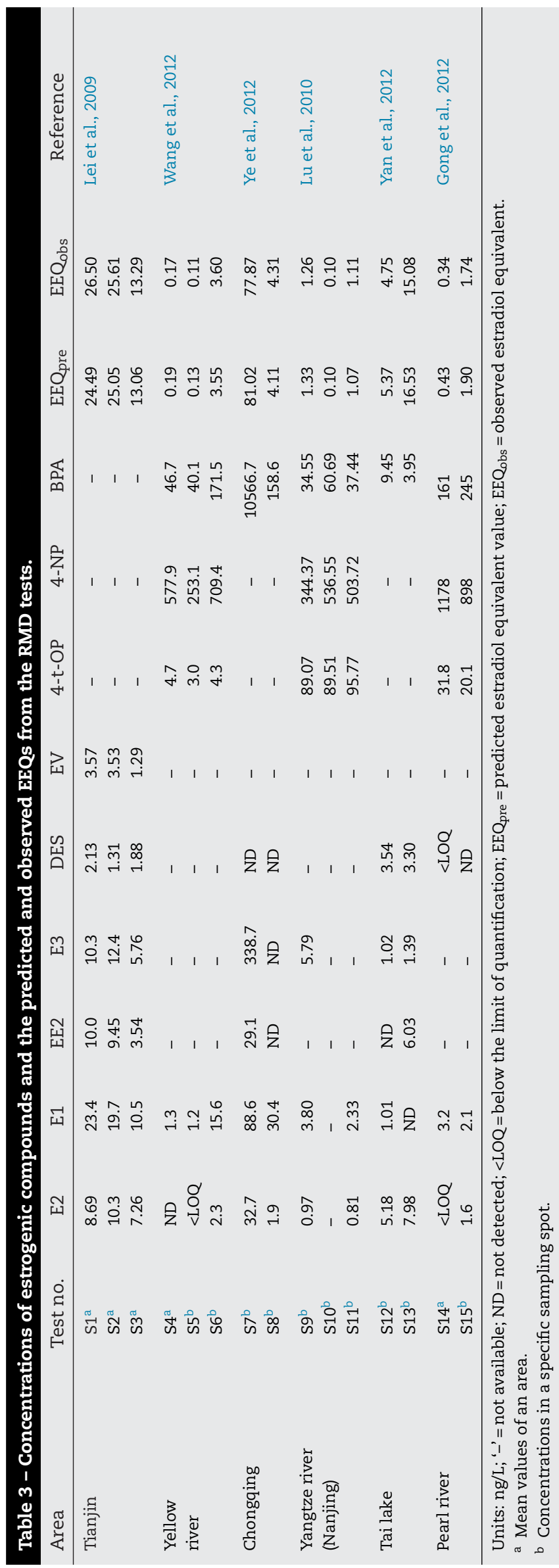

sample and the blank at $420 \mathrm{~nm}$, respectively, OD600 is the OD of the test culture at $600 \mathrm{~nm}$, $t$ is the duration of the enzymatic reaction incubation, $V$ is the volume of the test culture, and $D$ is the dilution factor.

\subsection{Data analysis for single chemicals}

Concentration-response curves (scatter plots of the normalized $U$ value versus log concentration) for single chemicals were constructed and analyzed using regression analysis in Sigmaplot 11.0 (SPSS Inc., Chicago, IL, USA). Because of the good fit for the original data, the logistic function was chosen to run the regression, which can be expressed as the following:

Logistic function : $\quad E=b+\frac{a}{1+\left(x / x_{0}\right)^{|p|}}$

Inverse logistic function : $\quad x=x_{0} \times \sqrt[|p|]{\left(\frac{a}{E-b}\right)-1}$

where $E$ is the yeast assay inductive effect, $x$ is the test chemical concentration, $a, b, x_{0}$, and $p$ are parameters that represent the maximum effect, the minimum effect, the concentration for the half-maximum effect (i.e., $\mathrm{EC}_{50}$ ), and the steepness of the concentration-response curve, respectively. REP was calculated using the $\mathrm{EC}_{50}$ values of $\mathrm{E} 2$ and test chemicals.

\subsection{Calculation of predicted mixture toxicities}

For the EED mixtures, two classic non-interaction models, CA and RA, were used to predict the combined estrogenic effects. A common expression for CA is:

$E C x_{\operatorname{mix}}=\left(\sum_{i=1}^{n} \frac{p_{i}}{\operatorname{ECx} x_{i}}\right)^{-1}$

where $\mathrm{EC} \mathrm{x}_{\text {mix }}$ and $\mathrm{EC} \mathrm{x}_{\mathrm{i}}$ are the concentrations in the mixture and of the ith component which produces effect $x$, respectively, and $p_{i}$ is the concentration proportion calculated as $p_{i}=c_{i} / \sum c_{i}$ (Backhaus et al., 2000).

The RA model is expressed using the following equation:

$E\left(c_{\text {mix }}\right)=1-\prod_{i=1}^{n}\left(1-E\left(c_{i}\right)\right)$

where $c_{\text {mix }}$ is the sum of the concentrations of all components, and $E\left(c_{\text {mix }}\right)$ and $E\left(c_{i}\right)$ are the effects of the whole mixture and the ith component, respectively (Faust et al., 2003).

For the RMD mixtures, the predicted EEQs of 15 samples were gained based on CA model, in a similar way to the toxic equivalency factor method (Van den Berg et al., 1998):

$\mathrm{EEQ}_{\text {pre }}=\sum_{i=1}^{n}\left(c_{i} \times \mathrm{REP}_{\mathrm{i}}\right)$

where $c_{i}$ and $\mathrm{REP}_{i}$ are the concentration and REP for each test chemical. The predictability of the CA was evaluated by comparing the predicted (calculated, or concentration-derived) 


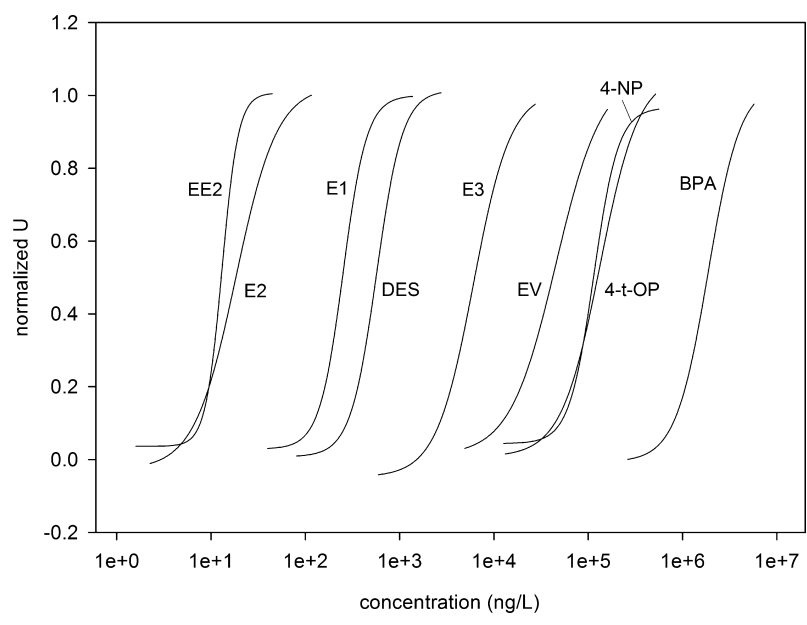

Fig. 1 - Concentration-response curves for individually tested mixture compounds.

EEQ with the observed (experimental, or bioassay-derived) EEQ.

\section{Results}

\subsection{Individual estrogenic effects of the test chemicals}

All chemicals showed concentration-dependent increases in $\beta$-galactosidase activity by inducing the enzyme production. Almost all of the concentration-response curves were parallel, and the logistic regression results were shown in Fig. 1. Based on the $\mathrm{EC}_{50}$ and REP for each chemical (Table 1 ), the estrogenic effect on the recombinant gene yeast was found to be in the order EE2 $>$ E2 $>$ E1 $>$ DES $>$ E3 $>$ EV $>4-N P>4$-t-OP $>$ BPA.

\subsection{Combined effect of mixtures in EED tests}

Sixteen mixtures containing different components and concentration ratios of the test chemicals were created by following the equivalent effect principle and using the test chemicals' $\mathrm{EC}_{50} \mathrm{~s}$ and REPs (Table 2), and the observed and predicted combined effects for these mixtures were shown in Fig. 2. From this graph, it was visualized that the CA line (black solid one) was always between the $95 \%$ confidence intervals (gray dashed lines) of the observed values at every concentration ratio and level. In addition, the $\mathrm{EC}_{50} \mathrm{~s}$ calculated using CA were closer to the observation than those obtained by RA (Table 2).

\subsection{Combined effect of mixtures in RMD tests}

Fig. 3a showed the relationship between concentration multiples and normalized Us for RMD mixtures. The EC 50 was not a concentration of $\mathrm{ng} / \mathrm{L}$, but the folds of concentration levels at which $50 \%$ of the estrogenic activity was achieved. Observed EEQs were gained according to these $\mathrm{EC}_{50} \mathrm{~s}$ (Table 3). For all samples, the EEQpres were nearly equal to the corresponding $E_{E Q}{ }_{0 b s} s$. The plot with calculated EEQs on the $x$-axis and the experimental EEQs on the $y$-axis showed that the 15 data points were very close to the theoretical line $x-y=0$, with a coefficient of determination $\left(R^{2}\right)$ of 0.9971 (Fig. 3b).

\section{Discussion}

The combined effects of EDCs started to draw increased attention when the strong synergistic effects in estrogenic mixtures were reported (Arnold et al., 1996). Although the paper was retracted the following year because the result was lack of reproducibility in other laboratories (McLachlan, 1997), it led to academic concern and intense follow-up research. There have been lots of researches to study the effects of estrogenic mixtures on organisms ranging from recombinant yeasts and estrogen-sensitive cells (Arnold et al., 1997; Payne et al., 2001; Rajapakse et al., 2004; Silva et al., 2011, 2002; Suzuki et al., 2001) to vertebrates such as fish and mice (Brian et al., 2007; Ramamoorthy et al., 1997; Ribeiro et al., 2012; Sun et al., 2009; Thorpe et al., 2005; Tinwell and Ashby, 2004). Among these test organisms, the recombinant human ER gene yeast obtained wide application because it provided not only fast and sensitive detection but also single MoA and ToA. In our lab, a recombinant yeast strain - which was utilized in this study - was established previously (Li et al., 2008b) by using the two-hybrid yeast technique. When the yeast cells are exposed to an estrogenic substance such as E2, ER in the cytoplasm is activated by binding the ligand. Then, the ER-E2 complex interacts with the co-activator in nuclear to form the trimer. This brought the binding domain and activating domain of Gal4 protein into proximity, and permitted the transcription of downstream reporter gene lac-Z. However, if a variety of ligands exist simultaneously, the behavior between them and ERs may change due to their different concentrations and receptor binding abilities, both of which are critical influences on the final effects.

The nine selected substances have frequently been found, by chemical analysis, at relatively high concentrations in the aquatic system of China, and all of them have been associated with endocrine disrupting effects (Gong et al., 2012; Lei et al., 2009; Liu et al., 2012; Lu et al., 2010; Sun et al., 2008; Wang et al., 2012; Yan et al., 2012; Ye et al., 2012). Thus, we chose them as representative estrogen-like chemicals that are present in the water environment. Considering the estrogenic potencies of chemicals varying with species and bioassay endpoint, the potency values obtained from the two-hybrid yeast assay for individual substances were compared with those reported in the literature using other methods. We found that our estrogenic activity order for the test chemicals was close to, and the $\mathrm{EC}_{50}$ values were slightly lower than most of the published ones (Brian et al., 2005; Correia et al., 2007; Folmar et al., 2002; Liu et al., 2009; Thorpe et al., 2005), which illustrates the reliability and high sensitivity of our yeast strain.

The transcription and translation process in the recombinant gene two-hybrid yeast assay can only be driven when substances with the ability to bind to the assay-specific receptor are present. Therefore, every component in a mixture acts similarly, competitively interacting with the same molecular target sites, which meets the strict demands of CA model (Groten, 2000; Pöch, 1993). According to the results using different experimental designs, it is obvious that the observed 

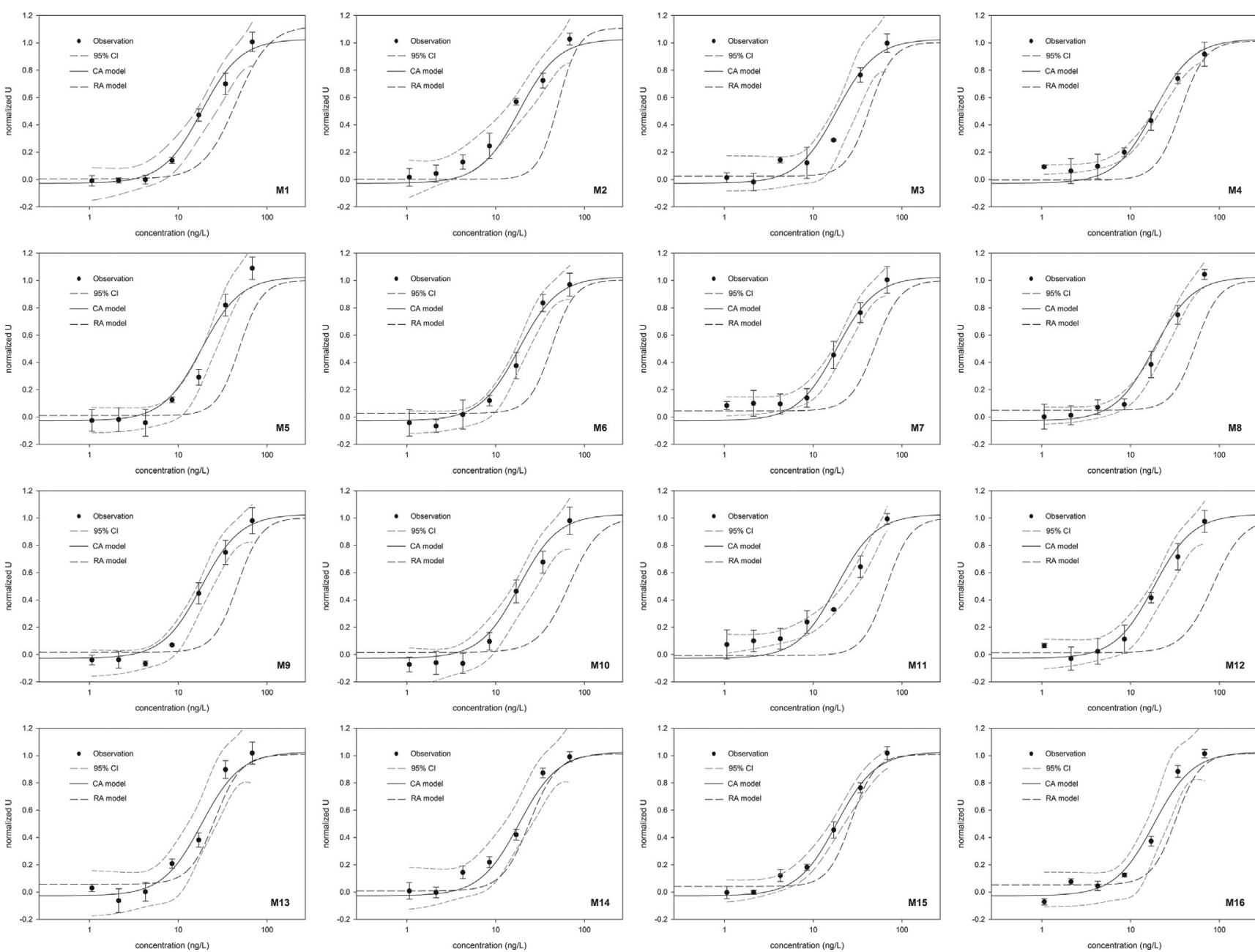

Fig. 2 - Observed results and predicted effects of each EED mixture. Concentrations are presented as estradiol equivalent (EEQ, ng/L). The black points are observed values, and each normalized $U$ is expressed as mean value \pm the standard deviation. The gray dashed lines, black solid lines, and black dashed lines are the $95 \%$ confidence intervals around the observations, the CA model predictions and the RA model predictions, respectively.
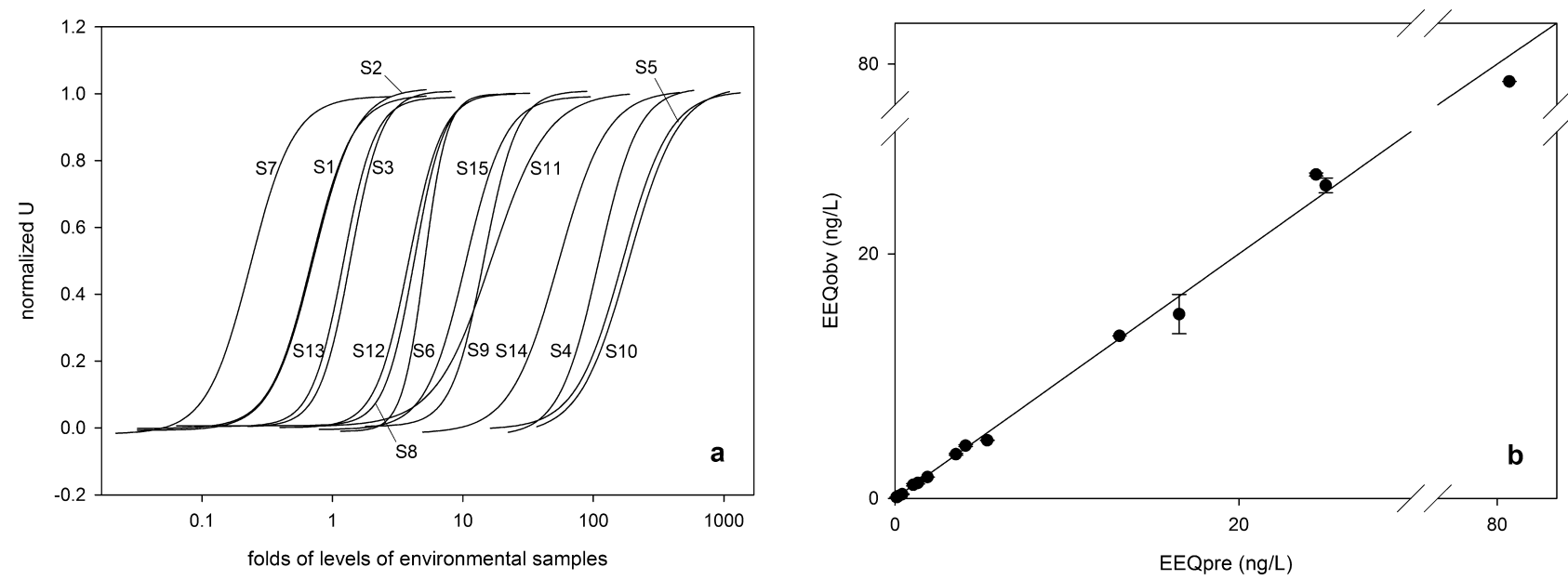

Fig. 3 - Observed and predicted results in RMD tests. (a) Regression models for the estrogenic effect of fifteen mixtures on the $\beta$-galactosidase activity in recombinant yeast cells. According to the concentrations of Table 3, 0.1, 1, 10, 100 and 1000 folds of levels which mimic the surface water or wastewater samples in China were tested. (b) Predicted and observed EEQs for each RMD mixture with the theoretical line $x-y=0$. 
effect of ER binding was always close to the prediction of CA. In EED study, no significant deviations were found from additivity, even for weak estrogenic chemicals. For the 16 mixtures, the results conformed to CA model better in the concentration range we tested. The excellent agreement between observations and predictions of the RMD study further proved that the EEQ method could provide a useful and convenient way for assessing the combined effects of xenoestrogens at concentrations below those used in EED (i.e., at environmental concentrations). Our results suggest that when all of the test chemicals acted through the same MoA, CA and EEQ are satisfactory predictors which are unaffected by the number, concentration ratio, or actual concentration of the mixture components.

We also investigated the validity of the RA model in the first part of our study. RA underestimated the effect of all 16 mixtures, demonstrating that it was unsuitable for assessing the effects of estrogenic chemicals in this assay. This may be because of the fundamentals of the yeast assay: RA model is not the optimal choice when only similarly acting chemicals can activate the yeast system (Backhaus et al., 2004; Drescher and Boedeker, 1995; Faust et al., 2003).

As shown above, if the number of involved MoAs can be limited to one, although the concentration of mixture components increases from environmental level (RMD) to tens of thousands of times (EED), CA model can offer preciser predictions on the two-hybrid yeast strain than RA. And for convenience, its derived EEQ method is recommended in environmental study. That also explains by using the chemical analysis data of mixtures, it is feasible to calculate the estrogenic effect (here refers to the ER-binding capacity) with considerable accuracy. The prediction deviations of EEQ in actual use may be the result of other impact factors, such as the disturbance of unknown chemicals in water sample or the interaction of different pathways in test organisms. Additionally, it is true that when the EEQ of chemical mixture is higher than the maximum-effect-concentration of E2 (68.1 ng/L in exposure culture or $13.6 \mu \mathrm{g} / \mathrm{L}$ in DMSO), the competitive binding of components to ER will result in the failure of CA prediction and create a false impression of antagonism. However, this can be avoided by diluting the test samples.

Here we take two cases as the example to explain how to get information about estrogenic effect and its main contributors by analyzing the concentrations of mixture chemicals and summing their EEQ values. Firstly, Gong et al. (2012) studied the distribution of EDCs in water from the Pearl River in China. They found that the mean concentrations (ng/L) of E1, 4-t-OP, 4-NP and BPA were 3.2, 31.8, 1178 and 161, respectively (S14 in RMD), while the EEQ values (ng/L) were $0.23,4.4 \times 10^{-3}, 0.19$ and $1.6 \times 10^{-3}$ after conversion. In spite of the higher concentration of three phenols, E1 is still the most potent estrogenic chemical due to its strong binding capacity with ER. Another study examined the content of EDCs in a sewage-treatment plant (Zhou et al., 2012), and the result showed that the average concentrations (ng/L) were 64.8 and 22.8 (E2), 171.5 and 49.9 (EE2), 115.3 and 50.9 (4-NP), 920.7 and 84.3 (BPA) in the influents and effluents, respectively. Thinking through the aspect of EEQ, the corresponding adjusted concentrations (ng/L) were 64.8 and 22.8 (E2), 240.5 and 70.0 (EE2), 0.019 and 0.008 (4$\mathrm{NP}), 0.009$ and 0.001 (BPA). The concentrations of these four substances do not appear to be much different from each other, all of which are in the range of tens to hundreds of $\mathrm{ng} / \mathrm{L}$; whereas their biological effects vary by several orders of magnitude. Because of its high concentration and REP value, EE2 becomes the main contributor to estrogenic effect followed by E2, while 4-NP and BPA scarcely make a contribution.

The successful implementation of the CA and EEQ in singleMoA assays and the likelihood of synergism appearing in more complex organisms highlights the limitations of existing environmental standards and risk assessment approaches, which are always established upon the basis of a single compound. In our study, good agreement between predicted and observed effects showed that even if the concentration of every individual estrogenic substance in a mixture is less than its no observable effect concentration (NOEC), it is possible that several chemicals with similar MoAs may induce an observable and adverse effect when acting in combination, which is similar to the description of Hood (2005).

In summary, this study demonstrated that the logistic function could describe the concentration-response relationship of either single or multiple components well, while CA and EEQ could predict the recombinant yeast assay results effectively, even for mixtures containing a range of estrogenic chemical compositions and concentrations. At the molecular level without any disturbance of antiestrogens and other MoAs, the mixture toxicity was proved to be additive. Therefore, considering that the present control standards of pollutants and water quality guidelines are mainly based on single chemical toxicities, it is predictable that with the development of combined effect studies, the effect-based quality criteria for aquatic environment will receive more attention in the future.

\section{Conflict of interest}

The authors declare that there are no conflicts of interest.

\section{Transparency document}

The Transparency document associated with this article can be found in the online version.

\section{Acknowledgements}

We gratefully acknowledge the support of the National High Technology Research and Development Program of China (2012AA06A302) and the National Natural Science Foundation of China (Grant No. NSFC 21307131).

\section{REF E R E N C E S}

Arnold, S.F., Bergeron, J.M., Tran, D.Q., Collins, B.M., Vonier, P.M., Crews, D., Toscano, W.A., McLachlan, J.A., 1997. Synergistic responses of steroidal estrogens in vitro (yeast) and in vivo (turtles). Biochem. Biophys. Res. Commun. 235, 336-342.

Arnold, S.F., Klotz, D.M., Collins, B.M., Vonier, P.M., Guillette Jr., L.J., McLachlan, J.A., 1996. Synergistic activation of estrogen receptor with combinations of environmental chemicals. Science 272, 1489-1492. 
Backhaus, T., Arrhenius, A., Blanck, H., 2004. Toxicity of a mixture of dissimilarly acting substances to natural algal communities: predictive power and limitations of independent action and concentration addition. Environ. Sci. Technol. 38, 6363-6370.

Backhaus, T., Scholze, M., Grimme, L.H., 2000. The single substance and mixture toxicity of quinolones to the bioluminescent bacterium Vibrio fischeri. Aquat. Toxicol. 49, 49-61.

Beck, I.C., Bruhn, R., Gandrass, J., 2006. Bioassay-directed fractionation for analyzing estrogens in surface waters of the German Baltic Sea. Acta Hydrochim. Hydrobiol. 34, 560-567.

Bliss, C.I., 1939. The toxicity of poisons applied jointly. Ann. Appl. Biol. 26, 585-615.

Brian, J.V., Harris, C.A., Scholze, M., Backhaus, T., Booy, P., Lamoree, M., Pojana, G., Jonkers, N., Runnalls, T., Bonfà, A., Marcomini, A., Sumpter, J.P., 2005. Accurate prediction of the response of freshwater fish to a mixture of estrogenic chemicals. Environ. Health Perspect. 113, 721-728.

Brian, J.V., Harris, C.A., Scholze, M., Kortenkamp, A., Booy, P., Lamoree, M., Pojana, G., Jonkers, N., Marcomini, A., Sumpter, J.P., 2007. Evidence of estrogenic mixture effects on the reproductive performance of fish. Environ. Sci. Technol. 41, 337-344.

Cargouët, M., Perdiz, D., Mouatassim-Souali, A., Tamisier-Karolak, S., Levi, Y., 2004. Assessment of river contamination by estrogenic compounds in Paris area (France). Sci. Total Environ. 324, 55-66.

Correia, A.D., Freitas, S., Scholze, M., Goncalves, J.F., Booij, P., Lamoree, M.H., Mañanós, E., Reis-Henriques, M.A., 2007. Mixtures of estrogenic chemicals enhance vitellogenic response in sea bass. Environ. Health Perspect. 115, 115-121.

Drescher, K., Boedeker, W., 1995. Assessment of the combined effects of substances: the relationship between concentration addition and independent action. Biometrics 51, 716-730.

Faust, M., Altenburger, R., Backhaus, T., Blanck, H., Boedeker, W., Gramatica, P., Hamer, V., Scholze, M., Vighi, M., Grimme, L.H., 2003. Joint algal toxicity of 16 dissimilarly acting chemicals is predictable by the concept of independent action. Aquat. Toxicol. 63, 43-63.

Folmar, L.C., Hemmer, M.J., Denslow, N.D., Kroll, K., Chen, J., Cheek, A., Richman, H., Meredith, H., Grau, E.G., 2002. A comparison of the estrogenic potencies of estradiol, ethynylestradiol, diethylstilbestrol, nonylphenol and methoxychlor in vivo and in vitro. Aquat. Toxicol. 60, 101-110.

Furuichi, T., Kannan, K., Giesy, J.P., Masunaga, S., 2004. Contribution of known endocrine disrupting substances to the estrogenic activity in Tama River water samples from Japan using instrumental analysis and in vitro reporter gene assay. Water Res. 38, 4491-4501.

Gong, J., Ran, Y., Chen, D.Y., Yang, Y., Zeng, E.Y., 2012. Association of endocrine-disrupting chemicals with total organic carbon in riverine water and suspended particulate matter from the Pearl River, China. Environ. Toxicol. Chem. 31, 2456-2464.

Groten, J.P., 2000. Mixtures and interactions. Food Chem. Toxicol. 38 (Suppl. 1), S65-S71.

Hood, E., 2005. Are EDCs blurring issues of gender? Environ. Health Perspect. 113, A670-A677.

Hotchkiss, A.K., Rider, C.V., Blystone, C.R., Wilson, V.S., Hartig, P.C., Ankley, G.T., Foster, P.M., Gray, C.L., Gray, L.E., 2008. Fifteen years after Wingspread - environmental endocrine disrupters and human and wildlife health: where we are today and where we need to go. Toxicol. Sci. 105, 235-259.

Jiang, W.W., Yan, Y., Ma, M., Wang, D.H., Luo, Q., Wang, Z.J., Satyanarayanan, S.K., 2012. Assessment of source water contamination by estrogenic disrupting compounds in China. J. Environ. Sci. 24, 320-328.
Knox, C., Law, V., Jewison, T., Liu, P., Ly, S., Frolkis, A., Pon, A., Banco, K., Mak, C., Neveu, V., Djoumbou, Y., Eisner, R., Guo, A.C., Wishart, D.S., 2011. DrugBank 3.0: a comprehensive resource for 'Omics' research on drugs. Nucleic Acids Res. 39, D1035-D1041.

Lavado, R., Loyo-Rosales, J.E., Folyd, E., Kolodziej, E.P., Snyder, S.A., Sedlak, D.L., Schlenk, D., 2009. Site-specific profiles of estrogenic activity in agricultural areas of California's inland waters. Environ. Sci. Technol. 43, 9110-9116.

Lei, B.L., Huang, S.B., Zhou, Y.Q., Wang, D.H., Wang, Z.J., 2009. Levels of six estrogens in water and sediment from three rivers in Tianjin area, China. Chemosphere 76, 36-42.

Li, J., Li, N., Ma, M., Giesy, J.P., Wang, Z.J., 2008a. In vitro profiling of the endocrine disrupting potency of organochlorine pesticides. Toxicol. Lett. 183, 65-71.

Li, J., Ma, M., Rao, K.F., Wang, Z.J., 2008b. Construction the recombinant human estrogen receptor ( $\mathrm{hER}$ ) gene yeast using two-hybrid yeast technique. Asian J. Ecotoxicol. 3, 21-26.

Liscio, C., Magi, E., Carro, M.D., Suter, M.J.F., Vermeirssen, E.L.M., 2009. Combining passive samplers and biomonitors to evaluate endocrine disrupting compounds in a wastewater treatment plant by LC/MS/MS and bioassay analyses. Environ. Pollut. 157, 2716-2721.

Liu, S., Ying, G.G., Zhou, L.J., Zhang, R.Q., Chen, Z.F., Lai, H.J., 2012. Steroids in a typical swine farm and their release into the environment. Water Res. 46, 3754-3768.

Liu, Y., Li, N., Ma, M., Rao, K.F., Wang, Z.J., 2009. Comparative study of phenolic compounds estrogenic and anti-estrogenic activities. China Environ. Sci. 29, 873-878.

Loewe, S., 1928. Die quantitativen Probleme der Pharmarkologic. Ergeb. Physiol. 27, 47-187.

Lu, G.H., Song, W.T., Wang, C., Yan, Z.H., 2010. Assessment of in vivo estrogenic response and the identification of environmental estrogens in the Yangtze River (Nanjing section). Chemosphere 80, 982-990.

Mahomed, S.I., Voyi, K.V.V., Aneck-Hahn, N.H., de Jager, C., 2008. Oestrogenicity and chemical target analysis of water from small-sized industries in Pretoria, South Africa. Water SA 34, 357-363.

Matthiessen, P., Arnold, D., Johnson, A.C., Pepper, T.J., Pottinger, T.G., Pulman, K.G.T., 2006. Contamination of headwater streams in the United Kingdom by oestrogenic hormones from livestock farms. Sci. Total Environ. 367, 616-630.

McLachlan, J.A., 1997. Synergistic effect of environmental estrogens: report withdrawn. Science 277, 462-463.

Payne, J., Scholze, M., Kortenkamp, A., 2001. Mixtures of four organochlorines enhance human breast cancer cell proliferation. Environ. Health Perspect. 109, 391-397.

Peng, X.Z., Wang, Z.D., Yang, C., Chen, F.R., Mai, B.X., 2006. Simultaneous determination of endocrine-disrupting phenols and steroid estrogens in sediment by gas chromatography-mass spectrometry. J. Chromatogr. A 1116, $51-56$.

Petrovic, M., Eljarrat, E., Lopez de Alda, M.J., Barceló, D., 2004. Endocrine disrupting compounds and other emerging contaminants in the environment: a survey on new monitoring strategies and occurrence data. Anal. Bioanal. Chem. 378, 549-562.

Pöch, G., 1993. Combined Effects of Drugs and Toxic Agents. Modern Evaluation in Theory and Practice. Springer, Berlin, Germany.

Rajapakse, N., Silva, E., Scholze, M., Kortenkamp, A., 2004. Deviation from additivity with estrogenic mixtures containing 4-nonylphenol and 4-tert-octylphenol detected in the E-SCREEN assay. Environ. Sci. Technol. 38, 6343-6352.

Ramamoorthy, K., Vyhlidal, C., Wang, F., Chen, I.C., Safe, S., McDonnell, D.P., Leonard, L.S., Gaido, K.W., 1997. Additive 
estrogenic activities of a binary mixture of $2^{\prime}, 4^{\prime}, 6^{\prime}$-trichloroand $2^{\prime}, 3^{\prime}, 4^{\prime}, 5^{\prime}$-tetrachloro-4-biphenylol. Toxicol. Appl. Pharmacol. 147, 93-100.

Ribeiro, C., Urbatzka, R., Castro, L.F.C., Carrola, J., Fontainhas-Fernandes, A., Monteiro, R.A.F., Rocha, E., Rocha, M.J., 2012. In vitro exposure of Nile tilapia (Oreochromis niloticus) testis to estrogenic endocrine disrupting chemicals: mRNA expression of genes encoding steroidogenic enzymes. Toxicol. Mech. Method 22, 47-53.

Sheeler, C.Q., Dudley, M.W., Khan, S.A., 1999. Environmental estrogens induce transcriptionally active estrogen receptor dimers in yeast: activity potentiated by the coactivator RIP140. Environ. Health Perspect. 108, 97-103.

Silva, E., Rajapakse, N., Kortenkamp, A., 2002. Something from nothing - eight weak estrogenic chemicals combined at concentrations below NOECs produce significant mixture effects. Environ. Sci. Technol. 36, 1751-1756.

Silva, E., Rajapakse, N., Scholze, M., Backhaus, T., Ermler, S., Kortenkamp, A., 2011. Joint effects of heterogeneousestrogenic chemicals in the E-Screen exploring the applicability of concentration addition. Toxicol. Sci. 122, 383-394.

Sun, L.W., Zha, J.M., Wang, Z.J., 2009. Interactions between estrogenic chemicals in binary mixtures investigated using vitellogenin induction and factorial analysis. Chemosphere $75,410-415$.

Sun, Q.F., Deng, S.B., Huang, J., Shen, G., Yu, G., 2008. Contributors to estrogenic activity in wastewater from a large wastewater treatment plant in Beijing, China. Environ. Toxicol. Pharmacol. 25, 20-26.

Suzuki, T., Ide, K., Ishida, M., 2001. Response of MCF-7 human breast cancer cells to some binary mixtures of oestrogenic compounds in-vitro. J. Pharm. Pharmacol. 53, 1549-1554.

Tetko, I.V., Gasteiger, J., Todeschini, R., Mauri, A., Livingstone, D., Ertl, P., Palyulin, V.A., Radchenko, E.V., Zefirov, N.S., Makarenko, A.S., Tanchuk, V.Y., Prokopenko, V.V., 2005. Virtual computational chemistry laboratory - design and description. J. Comput. Aided Mol. Des. 19, 453-463.

Thorpe, K.L., Gross-Sorokin, M., Johnson, I., Brighty, G., Tyler, C.R., 2005. An assessment of the model of concentration addition for predicting the estrogenic activity of chemical mixtures in wastewater treatment works effluents. Environ. Health Perspect. 114 (Suppl. 1), 90-97.
Tinwell, H., Ashby, J., 2004. Sensitivity of the immature rat uterotrophic assay to mixtures of estrogens. Environ. Health Perspect. 112, 575-582.

USEPA (United States Environmental Protection Agency), 2000. Supplementary guidance for conducting health risk assessment of chemical mixtures. In: Risk Assessment Forum, Washington, DC.

Van den Berg, M., Birnbaum, L., Bosveld, A.T.C., Brunström, B., Cook, P., Feeley, M., Giesy, J.P., Hanberg, A., Hasegawa, R., Kennedy, S.W., Kubiak, T., Larsen, J.C., van Leeuwen, F.X.R., Liem, A.K.D., Nolt, C., Peterson, R.E., Poellinger, L., Safe, S., Schrenk, D., Tillitt, D., Tysklind, M., Younes, M., Waern, F., Zacharewski, T., 1998. Toxic equivalency factors (TEFs) for PCBs, PCDDs, PCDFs for humans and wildlife. Environ. Health Perspect. 106, 775-792.

Vandenberg, L.N., Colborn, T., Hayes, T.B., Heindel, J.J., Jacobs Jr., D.R., Lee, D.H., Shioda, T., Soto, A.M., vom Saal, F.S., Welshons, W.V., Zoeller, R.T., Myers, J.P., 2012. Hormones and endocrine-disrupting chemicals: low-dose effects and nonmonotonic dose responses. Endocr. Rev. 33, 378-455.

Villeneuve, D.L., Blankenship, A.L., Giesy, J.P., 2000. Derivation and application of relative potency estimates based on in vitro bioassay results. Environ. Toxicol. Chem. 19, 2835-2843.

Wang, L., Ying, G.G., Chen, F., Zhang, L.J., Zhao, J.L., Lai, H.J., Chen, Z.F., Tao, R., 2012. Monitoring of selected estrogenic compounds and estrogenic activity in surface water and sediment of the Yellow River in China using combined chemical and biological tools. Environ. Pollut. 165, 241-249.

Yan, Z.H., Lu, G.H., Liu, J.C., Jin, S.G., 2012. An integrated assessment of estrogenic contamination and feminization risk in fish in Taihu Lake, China. Ecotoxicol. Environ. Saf. 84, 334-340.

Ye, X., Guo, X.S., Cui, X., Zhang, X., Zhang, H., Wang, M.K., Qiu, L., Chen, S.H., 2012. Occurrence and removal of endocrine-disrupting chemicals in wastewater treatment plants in the Three Gorges Reservoir area, Chongqing, China. J. Environ. Monit. 14, 2204-2211.

Zha, J.M., Wang, Z.J., Wang, N., Ingersoll, C., 2007. Histological alternation and vitellogenin induction in adult rare minnow (Gobiocypris rarus) after exposure to ethynylestradiol and nonylphenol. Chemosphere 66, 488-495.

Zhou, H.D., Zhou, Y.F., Li, H., Wang, F.F., 2012. Fate and removal of selected endocrine-disrupting compounds in sewage using activated sludge treatment. Water Environ. J. 26, 435-444. 